
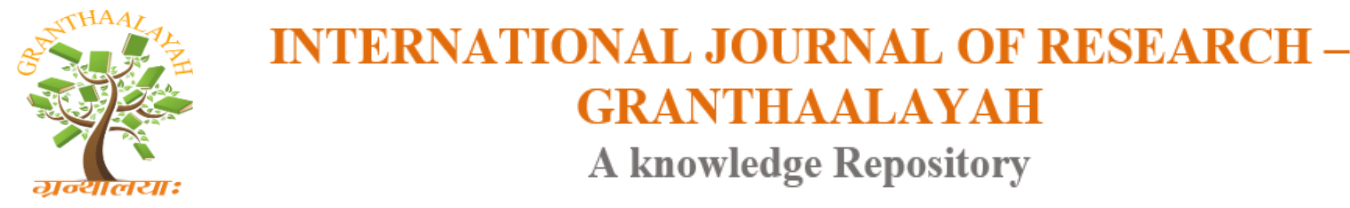

Management

\title{
EMPLOYEE PERCEPTION TOWARD THE IMPECT OF INFORMATION TECHNOLOGY IN HUMAN RESOURCE MANAGEMENT
}

\author{
Vinay Saxena $^{* 1}$, Rohit Sharma ${ }^{2}$ \\ ${ }^{* 1}$ Assistant Professor of Management Studies, Mahakal Institute of Management, \\ Ujjain, (MP), India \\ ${ }^{2}$ Scholar of Human Resource Studies, Mahakal Institute of Management, Ujjain, (MP), India
}

\begin{abstract}
Human Resource Information technology is a software solution for small to mid-sized businesses to help automate and manage their HR, payroll, management and accounting, recruiting selecting and many others. In the present time the role of IT in HRM is very wide and special An IT in HRM generally should provide the capability to more effectively plan, control and manage HR costs; achieve improved efficiency and quality in HR decision making; and improve employee and managerial productivity and effectiveness.

An IT in HRM offers HR, payroll, benefits, training, recruiting and compliance solutions

Most are flexibly designed with integrated databases, a comprehensive array of features, and powerful reporting functions and analysis capabilities that you need to manage your workforce. This can give back hours of the HR administrator's day previously spent attending to routine employee requests.

An IT in HRM also facilitates communication processes and saves paper by providing an easilyaccessible, centralized location for company policies, announcements, and links to external URL's. Employee activities such as time-off requests and W-4 form changes can be automated, resulting in faster approvals and less paperwork.

An affordable Human Resource Information System allows companies to manage their workforce through two powerful main components: HR \& Payroll. In addition to these essential software solutions, HRIS offers other options to help companies understand and fully utilize their workforce's collective skills, talents, and experiences.
\end{abstract}

Keywords: Information Technology Human Resource Management; Payroll; Benefits; Training; Recruiting and Compliance Solutions; Management.

Cite This Article: Vinay Saxena, and Rohit Sharma. (2017). "EMPLOYEE PERCEPTION TOWARD THE IMPECT OF INFORMATION TECHNOLOGY IN HUMAN RESOURCE MANAGEMENT." International Journal of Research - Granthaalayah, 5(7), 298-308. https://doi.org/10.29121/granthaalayah.v5.i7.2017.2135. 


\section{Introduction}

Information Technology (IT) is the application of computers and telecommunications equipment to store, retrieve, transmit and manipulate data, often in the context of a business or other enterprise.

The term is commonly used as a synonym for computers and computer networks, but it also encompasses other information distribution technologies such as television and telephones. Several industries are associated with information technology, including computer hardware, software, electronics, semiconductors, internet, telecom equipment, e-commerce and computer services.

Human Resource Management (HRM) is the part of management; human resource management is a process of planning, directing, controlling \& implementing of human resource.

Human Resource Management includes conducting job analyses, planning personnel needs, recruiting the right people for the job, orienting and training, managing wages and salaries, providing benefits and incentives, evaluating performance, resolving disputes, and communicating with all employees at all levels.

Information technology is expected to improve the performance of Human Resource Management (HRM) by shifting its focus from administration or personnel management to strategic HRM. The strategic role of HRM is supposed to add value to the HR function, and leads the essence of HR function to transform.

This study examines HR function, HR function transformation and Human Resource Information Technology (HRIT), by investigating the role of HRIT playing in HR function transformation process, and the interrelationship between them.

HRM describes a process of managing and utilizing the human resource of the organization. It includes various activities like recruitment and selection of the suitable candidates, providing training to improve their KSA (Knowledge, Skills and Abilities) and minimizing the gap between actual and the desired performances, assessing their performances for compensation and reward/incentive purposes, providing counselling for their succession planning and career advancement and finally separating the employee from the organization. Basically there are three types of e-HRM i.e. operational, relational and transformational E-HRM. Operational relates with the administrative functions of HR department, relational relates with providing information to the employees and creating virtual relationship among them so that they can be always connected, while transformational e-HRM focuses over the strategic orientation of the HR function.

It aims towards achieving the completive advantage by linking the HR function with business strategy to achieve the goals effectively. The rapid technological innovations have led organizations towards managing and sharing the data over virtual networks. 


\section{Significance of Using Technology in HRM}

Nowadays, small, medium and large organizations are making use of technology in delivering their HR services. HR and technology have become two concepts.

In the present cut-throat competitive environment, organizations are becoming more technologically in almost every business function.

E-HR aims at making information available to managers and employees at anytime and anywhere. Currently, an e-HR system may include enterprise resource planning software (ERP), HR service centers, interactive voice response, manager and employee portals and web applications.

So, a modern e-HR system allows employees to control their own personal information by updating records and making decisions, and allows managers to access information and data, conduct analyses, make decisions and communicate with others, without consulting the HR department.

\section{Human Resource Information System Advantages}

- Specialist can manage.

- Compliance with federal and state laws

- Streamline processes for recruitment and selection produce

- Analyses data and reports for internal and external use.

- Ease of use for qualification computer technology specialists.

- Accuracy of information

- Ability to perform HR audits using any combination of parameters.

- Employees and managers can locate answers and information quickly without the need to consult an HR representative every time.

- An HRIS can reduce the amount of paperwork and manual record keeping.

- It retrieves information quickly and accurately.

- It allows quick analysis of HR issues.

Modern HRIS can be seen as a spine of the company and it has to meet the needs of all stakeholders in the company. We can recognize three main groups :

1) HR professionals and directly involved in HR department.

2) Management of the company and

3) Employee.

Each of these groups has unique interest in the use of HRIS, and because of that, each of these groups of users have a special module(s) which can meet the needs.

HRIS can be ranging from strategic to operational level in one company, as we can see in Figure. 

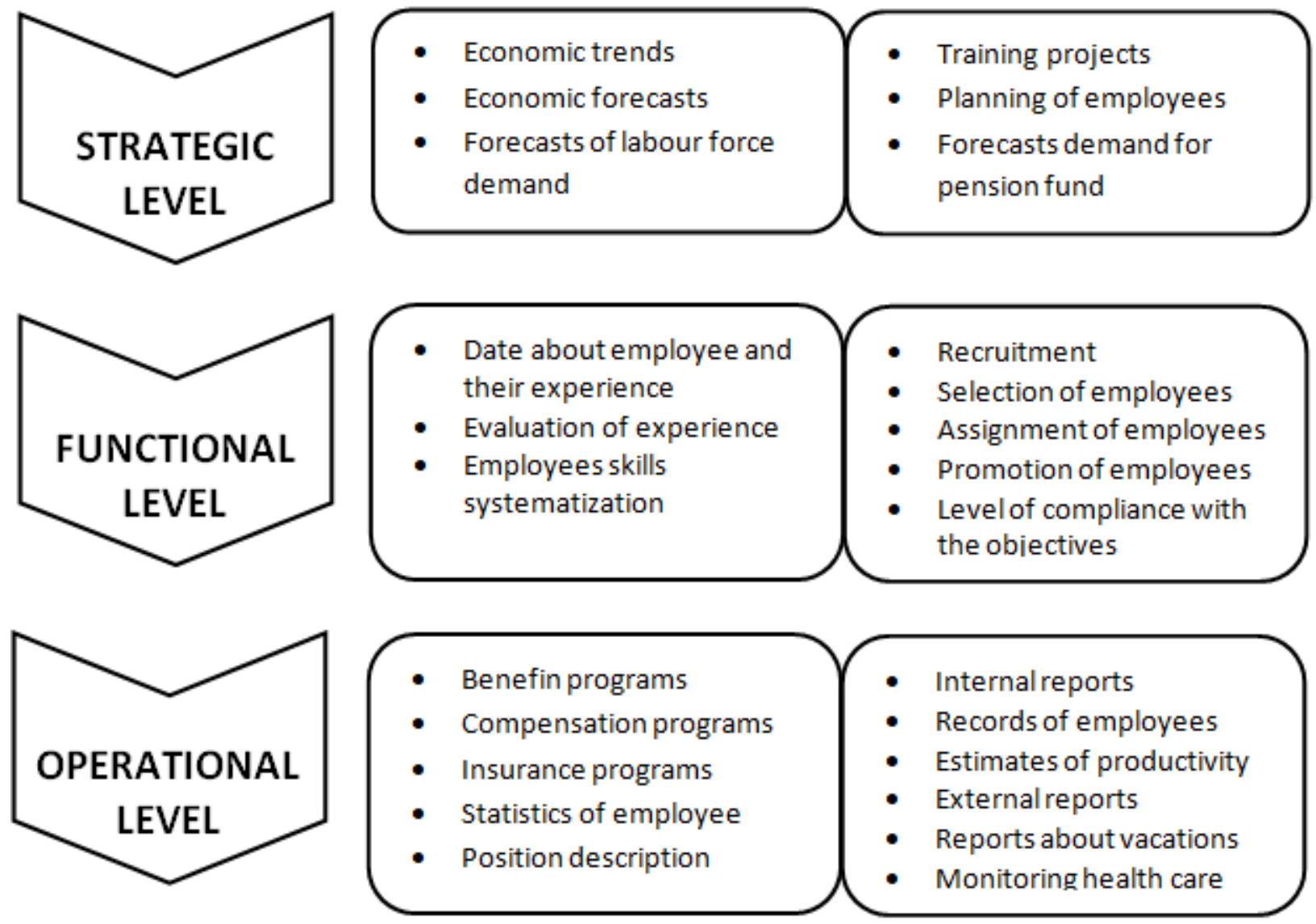

The HRIS achieved new dimension with development of computer networks. By then, only trained employees, mainly from the HR department could perform operations in separated computers or in mainframes, through a local network of terminals.

\section{Opportunities for Implementing IT with HR Functions}

1) Competitive Advantage: In today's organizations, creating, maintaining, measuring and leveraging intellectual capital are the main sources of competitive advantage. Providing employees with specific personalized applications through HRM portals means e-HRM can be a key method in the adoption of competitive adoption of competitive advantage through intellectual property.

2) Accessibility: Due to the transparency issue, whole information is readily available to all the employees either through internet or intranet. Any employee may access any information at any time easily. This helps in the embedding the concept of equity in the organizational policies. HR portals allow the employees to access all the required information at a single click.

3) Rapid and error free transactions: Technological innovations have increased the pace of service delivery in organizations. Human may commit mistakes while performing the administrative tasks but the technological systems performs the tasks error free. Due to timely delivery of services, the employees are happier and satisfied. It saves time in 
performing the task and also for correcting the errors. Therefore, technology in HR function leads an economical mechanism for delivering the HR services to its employees.

4) Interactive Atmosphere: Technology enhances rich interactions among the employees through the web based portals. Larger organizations then have more information needs and therefore can take more advantages from the information function. Moreover, large organizations also profit more by the collaboration function. With growing size organizations tend to increasingly spread over different buildings and locations. The resulting spatial segregation of relevant actors complicates.

\section{Challenges Associated with HR Technology}

1) Cost: Technology pulls cost. In implementing a technology based HR system, a huge initial investment is required. Once implemented, it reduces the operational costs. Large organizations may install HR portals/packages while it is difficult for a small or medium sized organization to afford them.

2) Acceptance: Before the implementation of technological innovations in the organization, HR itself is the biggest obstacle. Due to IT implementation various issues like Skills/Knowledge for its use, employment risks etc. always rise in its way.

3) Acceptance from the workforce is needed for utilizing it up to its fullest. In the information era, information and communication technology (ICT) is widespread and has become an integral part of almost all jobs occupied by knowledge workers. It increases the burden of the employees by spending more time connected.

4) Back-ups and Security Concerns: It requires maintaining a fully-fledged back-up system of the overall e-HR system. It leads the maintenance costs. One of the basic disadvantages of using E-HRM is that the data gets free accessible to all and anybody can access the strategic information and use it any way without any authorization. It is prone to corruption/hacking/data losses. Open assess to the databases destroys the personal information of the workers which may leads to illicit access.

5) Increasing Isolation: Due to the formation of virtual networks through intranet or webbased HR portals, the personal interaction among the employees has diminished. In the traditional systems, they interact with the administration department regarding their employment issues due to which they were also personally connected. But due to IT implementation they need not to go in the administration branch regarding such issues. They are isolated from each other and are connected virtually through such portals only.

6) More informed Employees: Due to easily accessibility and transparency, the employees are well informed about the market pay structures. It increases the accessibility of internal and external compensation information. This knowledge may force the organization to modify its compensation structures from time to time in order to comply with the present structure in other companies. It may sometimes, create problems for the organization.

\section{The Human Resource Information Systems (HRIS) Provide Overall}

1) Management of all employee information.

2) Reporting and analysis of employee information.

3) Company - related documents such as employee hand book, emergency evacuation procedures and safety guidelines. 
4) Benefits administration including enrolment, status changes and personal information updating.

5) Complete integration with payroll and other company financial software and accounting systems.

6) Application tracking and resume management.

\section{Role of Information Technology}

Information technology (IT) has become a vital and integral part of every business plan. From multi-national corporations who maintain mainframe systems and databases to small businesses that own a single computer, IT plays a role. The reasons for the omnipresent use of computer technology in business can best be determined by looking at how it is being used across the business world.

\section{In Most Cases HRIS Contains All or Most of the Following Modules}

- Collection and monitoring of applications for employment or online recruiting is an application that allows candidates to apply for a certain position in the company, but also for HR department to collect and process the received applications. In this module of HRIS the using of computer systems and networks are very important, especially because of online accesses to the system.

- Record keeping of all personal data is application which has database with data of all employees. It is very important for each company to have these data, and in most cases data must be standardized.

- Payroll Module automates the pay process by collecting data on employee time and attendance, calculating various deductions and taxes, and generating periodic pay cheques and employee tax reports. This module is often not fully part of the HRIS, because it is heavily integrated into the system for financial management of the company.

- Employee Self - Service in modern environment is module based on web technology which allows employee, together with professionals in HR department to manage the employee's database. With the right permission they can access their data with read-only or change status.

- Communication for many companies, email is the principal means of communication between employees, suppliers and customers. Email was one of the early drivers of the Internet, providing a simple and inexpensive means to communicate. Over the years, a number of other.

Communications tools have also evolved, allowing staff to communicate using live chat systems, online meeting tools and video-conferencing systems.

- Inventory Management: When it comes to managing inventory, organizations need to maintain enough stock to meet demand without investing in more than they require. Inventory management systems track the quantity of each item a company maintains, triggering an order of additional stock when the quantities fall below a pre-determined amount. These systems are best used when the inventory management system is connected to the point-of-sale (POS) system. 
- Data Management: The days of large file rooms, rows of filing cabinets and the mailing of documents is fading fast. Today, most companies store digital versions of documents on servers and storage devices. These documents become instantly available to everyone in the company, regardless of their geographical location. Companies are able to store and maintain a tremendous amount of historical data economically, and employees benefit from immediate access to the documents they need.

- Management Information System: Storing data is only a benefit if that data can be used effectively. Progressive companies use that data as part of their strategic planning process as well as the tactical execution of that strategy. Management Information Systems (MIS) enable companies to track sales data, expenses and productivity levels. The information can be used to track profitability over time, maximize return on investment and identify areas of improvement.

- Customer Relationship Managements: Companies are using IT to improve the way they design and manage customer relationships. Customer Relationship Management (CRM) systems capture every interaction a company has with a customer, so that a more enriching experience is possible. If a customer calls a call canter with an issue, the customer support representative will be able to see what the customer has purchased, view shipping information, call up the training manual for that item and effectively respond to the issue.

\section{Rational of Study}

Information technology is change has phase of business with the advantage of new technology. The business is obsessive new highest, better efficiency, more effectiveness, easy and convince has crude is due to Information technology.

In order to understand the impact of information technology on the effective of employee in the field of human resource. This study is undertaken. Flowing objective are as follows:

- Challenges in human resource management from technological advancement.

- To offer an adequate, comprehensive and on-going information system about people and jobs at a reasonable cost.

- To provide support for future planning and also for policy formulations.

- To facilitate monitoring of human resources demand and supply imbalance.

- To automate employee related information.

- To enable faster response to employee related services and faster HR related decisions and

- To offer data security and personal privacy.

- To know the role of information technology.

- To understand the advantage and disadvantages in information technology.

- To study the perception of different category of employees towards performance appraisal activities.

- To provide measure for the beneficiary of the individual and organization and increase the effectiveness and efficiency. 


\section{Objective}

The main objective of the study is to find Impact of Technology Advancement on Human Resource Performance. To achieve these main objectives, we need to achieve more sub objective like:-

- Challenges in human resource management from technological advancement.

- To offer an adequate, comprehensive and on-going information system about people and jobs at a reasonable cost.

- To provide support for future planning and also for policy formulations.

- To facilitate monitoring of human resources demand and supply imbalance.

- To automate employee related information.

- To enable faster response to employee related services and faster HR related decisions and.

- To offer data security and personal privacy.

- To know the role of information technology.

- To understand the advantage and disadvantages in information technology.

- To study the perception of different category of employees towards performance appraisal activities.

- To provide measure for the beneficiary of the individual and organization and increase the effectiveness and efficiency.

\section{1) Human Resource Planning}

With the help of technology build databases, they may maintain up-to date records of the current employees working in the organization and the requirements in each department. Being an information system of human

\section{2) Administration}

Through technology, a well maintained and updated database of employee records may be created. All the critical information related to the workforce like their name, address, e-mail, contact no., qualification, compensation benefits, experience, date of entry in organization, employment status (contract, permanent, full-time, part-time etc.) are centralized in a database which may be retrieved any time whenever required.

\section{3) Recruitment}

Web-based technologies have become a prominent means in recruiting the employees for the organization. Internet recruitment is nowadays is a hot approach for hiring talent. Online recruitment and the use of new emerging technologies have many advantages for the modern recruiter. It makes the process of finding candidates and new business opportunities quicker, cheaper and more efficient. The internet has caused the largest change to the recruitment process in the past decade acting as a link between employers and job seekers.

\section{4) Training and Development}

E-learning is a revolutionary way to empower a workforce with the skills and knowledge it needs to keep pace with a rapidly changing market. The e-learning module provided an effective vehicle for the delivery of training activities.

However, by linking the assessment process to the Human Resources database, the e-learning system supported processing quality by ensuring that only quailed and accredited employees were assignment to tasks requiring those skills and that the need for ongoing maintenance of critical competencies was efficiently met. 


\section{5) Compensation and other Benefits}

Technology has also made it straightforward to design and maintain the compensation channel of the overall workforce of the organization updated and error free. The e-compensation packages offer transparent and easy assessable information about the compensation structure of all the employees along with the compensation policies of the organization available to the employees round-the clock in a cost effective manner.

\section{6) Performance Evaluation}

The performance management effectively supports key executives and operational management by providing timely and relevant information from both within and outside the enterprise. EPerformance system is a competency - based system that measures people not only on goal attainment but also on the very competencies that are required for their role. To ensure success, one can choose to support all employee goals with competencies and competency ratings that will help achieve success.

\section{7) Implementation Expenses :}

Every business must consider start up costs when implementing any type of information technology system. In addition to the cost of hardware and software, some technology vendors require businesses to purchase user licenses for each employee that will be operating the system. Businesses must examine the cost of training employees in unfamiliar technology. Although basic information technology systems may be user friendly, advanced programs still require formal instruction by $\mathrm{n}$ expert consultant.

In addition to the start up expenses, information technology systems are expensive to maintain. Systems malfunction, and when they do, businesses must engage skilled technicians to troubleshoot and make the necessary repairs. These expenses present a major disadvantage of information technology in business, particularly to businesses that are entering the technology era for the first time.

\section{8) Job Elimination}

Implementing information technology into business operations can save a great deal of time during the completion of daily tasks. Paperwork is processed immediately, and financial transactions are automatically calculated. Although businesses may view this expediency as a boon, there are untoward effects to such levels of automation.

As technology improves, tasks that were formerly performed by human employees are now carried out by computer systems. For example, automated telephone answering systems have replaced live receptionists in many organizations. This leads to the elimination of jobs and, in some cases, alienation of clients. Unemployed specialists and once-loyal employees may have difficulty securing future employment.

\section{9) Security Breaches}

The ability to store information in an electronic database facilitates quicker, more efficient communication. In the past, an individual would sift through stacks of paper records to retrieve data. With properly implemented technology, information can be recovered at the touch of a button.

Although information technology systems allow business to be conducted at a faster pace, they are not without their flaws. Information technology systems are vulnerable to security breaches, particularly when they are accessible via the Internet, If appropriate measures are not in place, unauthorized individuals may assess confidential data Information may be altered, permanently destroyed or used for unsavoury purposes.

10) Limited data used. 
11) Selected area

12) Low rate of return duly filled in questionnaires.

13) Ambiguous replies omissions of certain questions; interpretation of omissions was difficult.

14) Most of the employees did not responded to the open ended questions.

15) Many employees did not take it kindly enough to fill up the questionnaire as it brings the disturbance during their work.

16) It was quite a time consuming process.

\section{Conclusion}

As a consequence of the advancement of information technologies and evolvement of e-HR organizations have become more competitive by reducing costs and improving productivity, quality and profitability in HRM area. 109 Modern businesses and industries are taking suitable steps for the implementation of IT in the key area of the management of human resources by enabling the employees to make their optimum contribution to the gaining of a competitive advantage.

This study investigates the extent and comparative impact of IT use on HRM functions in organizations from different sectors. It has also taken into account the usage pattern of different IT tools to perform different HRM functions in organizations.

Based on the survey data, the result firstly indicated that IT has significant impact on all sectors in terms of management and planning tasks and, secondly, that type of IT used varies significantly for the tasks of recruitment, and maintenance and development functions.

The findings also support the conclusion that the use of IT is pervasive in the organizations for their HRM activities. However, there is no standardization in the integration of computer software into main HRM activities. This may be explained by the gap between job requirements and the ability of employees to perform HRM tasks.

Low levels of integration of software and HRM functions can be related to fear based on ignorance and low levels of knowledge and training in IT. In general, organizations do not have portals exclusively for HR functions and use different computer software for similar HRM functions. This also means that these technologies are not systematically and maturely used for HRM functions included in the analysis in Turkey and this situation is expected to continue in the near future. With this backdrop, HR departments should spend more attention to the education and training of employees in HRM departments in the area of IT.

Future empirical studies should examine the impact of IT on more HR functions different organizations in other parts of the world to make a comprehensive assessment. Furthermore, in Turkey this study could also be conducted with more breadth and depth in terms of HRM functions and IT tools.

\section{References}

[1] C.B. Gupta, (2006), - Human Resource Management, 10th Edition. 
[2] Ghosh, (2008), - Human Resource Development, 8th Editon.

[3] Kothari. C.R., (2005), - Research Methodology Methods and Techniques, 4th Edition.

[4] L.R. Potty, (2011), - Research Methodology.

[5] Zorlu Senyucel, (2016), - Managing The Human Resource in the 21st century. 2nd Edition.

[6] http://theglobaljournals.com/paripex/file.php?val=april_2014_1397566831_01068_51.pdf

[7] http://www/atilim.edu.tr/ amishra/HRM.pdf

[8] www.ibmrdjournal.com/index.php/ibmrd/article/view/46706

\section{About Author's}

Prof. Vinay Saxena is working as assistant Professor in Management Studies in MIM, Ujjain (M.P.). He has done various degrees namely B.A., M.A., M.Sc., L.LB., M.B.A., L.LM., PGDMM, PGDEE, PGDLL, DTS respectively. He is currently pursuing M.A. in Human Physiology and has 15 years Teaching and Industrial Experience. He has published various research papers.

Rohit Sharma is pursuing Masters in Management Studies with Human Resource Management. He did his B.Com (H.) with 80\% from Vikram University, Ujjain (M.P.). He is active member of many NGO organizations in Ujjain (M.P.). He is working as councilor.

\footnotetext{
*Corresponding author.

E-mail address: saxena_vinay50@ rediffmail.com
} 